\title{
FAKTOR-FAKTOR YANG MEMPENGARUHI PENGEMBANGAN EKONOMI LOKAL (PEL) DI KOTA MEDAN (Studi Kasus Usaha Kecil Dan Menengah Sebagai Sektor Basis)
}

\author{
Anton Atno Parluhutan Sinaga \\ Universitas Methodist Indonesia Jl. Setia Budi Jl. Setia Budi Ps. II No.85, 20132, Indonesia \\ e-mail: uhn@uhn.ac.id
}

\begin{abstract}
The concept of Local Economic Development (LED) is an analytical tool that can be used to describe and measure economic conditions in a region. The territory in question may be administrative territory or region / region of particular business / commodity development, including small and medium enterprises (SMEs). Small and Medium Enterprises (SMEs) are part of the most strategic economic sector, concerning the livelihood of the people and is an important pillar in supporting and moving the joints of the economy in many countries.. SMEs play several important roles in Indonesia, one of them important players In Local Economic Development (LED) and community development. The purpose of this study is directed to determine the factors - factors that affect Local Economic Development with SMEs as the base sector in the city of Medan. The research method used in this research is Quantitative Descriptive Research Method. Data collection is done by using secondary and primary data. Then the analysis used to test the research hypothesis that has been determined by using the sample data obtained. The Inferential Statistics Method used in the analysis of this research data is Structural Equation Modeling (SEM). Descriptive result of this research is there are three variables have the average score of each - each variable is smaller than the middle threshold score 9. The three latent variables referred to include: social capital, socio-economic characteristics, and economic development policy However, when viewed From educational and skill perspectives, labor market and geographical characteristics greater than the middle threshold score 9. The results of this study are social capital, education and expertise, social characteristics, labor market, economic development policy and local culture are six factors Have a positive and significant impact on the succession of local economic development program of Medan city.
\end{abstract}

Keywords: Small and Medium Enterprises (SMES), Local Economic Development (LED)

\section{PENDAHULUAN}

Konsep pengembangan ekonomi lokal (PEL) telah memperoleh pengakuan luas selama dekade terakhir ini dan kemunginan akan segera menggantikan konsep spatial economic. Rogerson, (2003) mengatakan konsep dan strategi pengembangan ekonomi lokal (PEL) telah memperoleh penerimaan tersebar luas di seluruh dunia sebagai respon berbasis lokalitas terhadap tantangan yang ditimbulkan oleh globalisasi, devolusi, dan peluang tingkat lokal. Lebih lanjut Rogerson, (2003) memandang bahwa konsep PEL bukanlah hal yang dilakukan, tapi cara melakukan hal-hal.

Dalam merencanakan dan mengembangkan perekonomian lokal, konsep PEL membawa pemerintah lokal dan organisasi masyarakat untuk mengambil perspektif baru dan berbeda terhadap prakarsa pengembangan yang terencana dan terorganisir, dan komunitas besar atau kecil perlu memahami semiskin atau sekaya apapun pemerintah lokal, masyarakat dan sektor swasta adalah mitra kerja yang penting dalam proses pengembangan ekonomi.

Konsep PEL yang dikembangkan oleh Mayer (2006) telah memasukkan aspek ruang dalam model PEL-nya (Bappenas, 2006). Konsep PEL dapat merupakan alat analisis yang dapat digunakan untuk menggambarkan dan mengukur kondisi PEL di suatu wilayah. Wilayah yang dimaksud dapat berupa wilayah administratif ataupun wilayah/kawasan pengembangan usaha/komoditi unggulan tertentu, termasuk usaha kecil dan menengah (UKM). 
Usaha Kecil dan Menengah (UKM) merupakan bagian dari sektor ekonomi yang paling strategis, menyangkut hajat hidup orang banyak dan merupakan pilar penting didalam menopang dan menggerakan sendi-sendi perekonomian di banyak negara di dunia. Tambunan (2003) menyebutkan salah satu karakteristik dari dinamika dan kinerja ekonomi yang baik dengan laju pertumbuhan yang tinggi di negar-negara Newly Industrializing Countires (NICs) di Asia Timur dan Tenggara (Korea Selatan, Singapura, dan Taiwan) ditandai dengan kinerja UKM yang sangat efisien, produktif, memiliki tingkat daya saing yang tinggi, berorientasi pada ekspor dan responsif terhadap kebijakan-kebijakan pemerintah dalam pembangunan sektor swasta.

Dinas Koperasi UKM Kota Medan dalam Sinaga (2013) mencatat proporsi UKM Kota Medan didalam menggerakan perekonomian Kota Medan lebih besar dari proporsi UB, yaitu sebesar $46.12 \%$ atau jumlahnya hampir mencapai 2 kali lipat jumlah perusahaan besar di Kota Medan.

Tabel. 1. Kontribusi UKM Terhadap PDRB Kota Medan

\begin{tabular}{|c|c|c|c|}
\hline \multirow[t]{2}{*}{ No. } & \multicolumn{3}{|c|}{ Lapangan Usaha sIUDI } \\
\hline & & Jumlah (Juta) & Kontribusi (\%) \\
\hline 1 & Pertanian & $2.340 .771,21$ & 2,5 \\
\hline 2 & Penggalian & $2.910,46$ & 0 \\
\hline 3 & Industri Pengolahan & $13.464 .885,26$ & 14,38 \\
\hline 4 & Listrik,Gas dan AirMinum & $1.579 .106,41$ & 1,69 \\
\hline 5 & Bangunan & $9.830 .513,95$ & 10,5 \\
\hline 6 & $\begin{array}{l}\text { Perdagangan, } \\
\text { Hotel dan Restoran }\end{array}$ & $24.263 .410,06$ & 25,92 \\
\hline 7 & Pengangkutan dan Komunikasi & $17.804 .019,19$ & 19,02 \\
\hline 8 & $\begin{array}{l}\text { Keuangan, Ansuransi,Usaha Persewaan } \\
\text { Bangunan,Tanah \&Jasa Perusahaan }\end{array}$ & $14.142 .262,49$ & 15,11 \\
\hline 9 & Jasa-jasa & $10.182 .878,36$ & 10,88 \\
\hline \multicolumn{2}{|l|}{ Total } & SA $93.610 .757,40$ & 100 \\
\hline \multicolumn{2}{|c|}{ Usaha Besar } & & 60.20 \\
\hline \multicolumn{2}{|l|}{ UKM } & & 39.80 \\
\hline
\end{tabular}

Sumber : BPS Kota Medan, 2014

Tabel 1 diatas dapat mejelaskan bahwa dalam hal penyerapan tenaga kerja, hingga Akhir tahun 2012, UKM di Kota Medanberhasil menyerap tenaga kerja hingga 96 persen, namun dalam hal pembentukan PDRB, kontribusi UKM di Kota Medan masih relatif. kecil dan miris, yakni hanya 39.8\% atau lebih besar dari kontribusi usaha besar $60.2 \%$, dibawah kontribusi UKM terhadap PDRB Sumatera Propinsi Sumatera Utara 56.00\% dan Kontribusi UKM terhadap PDB Indonesia 57.56\%. Kondisi ini menunjukkan disamping UKM memiliki peran yang strategis dalam suatu perekonomian, disisi lain sarat dan rentan dengan berbagai permasalahan. Oleh karenanya, agar UKM senantiasa tetap eksis, dibutuhkan pemberdayaan yang komprehensif dan berkesinambungan.

Giaoutzi et. al. (1988) menegaskan UKM sebagai faktor pembangunan regional bersifat indegenous memiliki akar dengan struktur ekonomi lokal. Urata (2000) mengamati perkembangan UKM di Indonesia dan menegaskan bahwa UKM memainkan beberapa peran penting di Indonesia, satu diantaranya pemain penting dalam Pengembangan Ekonomi Lokal (PEL) dan pengembangan masyarakat. Idris (2007) dalam penelitiannya menemukan bahwa terdapat potensi pemberdayaan UKM di kawasan perbatasan berbasis komoditas dan aktivitas ekonomi dominan setempat, peningkatan ekspor dan pengembangan ekonomi lokal. 
Istilah Pengembangan Ekonomi Lokal (PEL) atau Local Economic Development (LED) berbasis UKM, bukanlah hal yang baru untuk diperbincangkan, terlebih untuk diimplementasikan. Sejak tahun 1960, istilah PEL telah diperkenalkan sebagai suatu pendekatan dalam pembangunan ekonomi regional. PEL pada hakekatnya merupakan suatu proses pembangunan ekonomi di mana stakeholders endogeneous (pemerintah, swasta, dan masyarakat) yang berperan aktif dalam mengelola sumber daya lokal untuk menciptakan lapangan kerja dan memberikan stimulus pada pertumbuhan ekonomi dan kesejahteraan masyarakat di wilayahnya. Berdasarkan pengertian di atas, jelas terlihat bahwa keberadaan PEL sangat penting dan sangat strategis didalam menggali berbagai sumber daya lokal yang dimiliki suatu wilayah. Adjie (2011) menyebutkan di samping meningkatkan PAD, PDRB; pendapatan masyarakat, berkurangnya pengangguran dan menurunkan tingkat kemiskinan juga meningkatnya kesejahteraan masyarakat.

UKM terbukti banyak memberikan kontribusi dalam pembangunan regional. Kritik utama terhadap kebijakan regional tradisional/klasik pada masa lalu adalah perhatiannya yang terfokus pada masuknya investasi (inwärd investment) baik dari domestik maupun investasi dari luar negeri. Kebijakan regional tradisional pada awalnya kurang memberikan perhatian yang cukup baik terhadap faktor-faktor pembangunan yang asli (indigenous development). Secara khusus, perhatiannya untuk menstimulasi perusahaan-perusahaan baru, seperti usaha kecil menengah dirasa sangat kurang.

Sebagai salah satu pilar perekonomian, pemberdayaan UKM di kawasan perkotaan jauh lebih penting dibandingkan pemberdayaan UKM di kawasan pedesaan. Hal ini karena kawasan perkotaan merupakan tempat bermuaranya sebagian besar aktivitas perekonomian dalam suatu wilayah. Bahkan kawasan perkotaan kerap sekali menjadi ikon perekonomian Nasional ataupun Regional (termasuk Kota Medan). ILO melaporkan fakta bahwa 60\% buruh di kota-kota negara berkembang diserap oleh sektor informal dan kegiatan pada usaha kecil dan menengah (UKM). Dilaporkan juga bahwa peran sektor UKM sangat penting karena mampu menciptakan pasar-pasar, mengembangkan perdagangan, mengelola sumber alam, mengurangi kemiskinan, membuka lapangan kerja, membangun masyarakat dan menghidupi keluarga pelaku UKM itu sendiri (Gasser, et. al., 2005 dan Reddy et.al., 2002).

Berbagai potensi, permasalahan dan pertanyaan-pertanyaan seputar Pengembangan Ekonomi Lokal (PEL) sebagaimana diuraikan di muka, merupakan ide yang menggagasi dilakukannya pengkajian yang lebih konkret, komprehensif dan terientegrasi yang selanjutnya dirangkum dalam satu rumusan judul penelitian ini: "Analisis Faktor Pengembangan Ekonomi Lokal (PEL) terhadap Kesejahteraan Masyarakat Kota Medan."

Berdasarkan hasil inventarisir potensi sumber daya yang ada di Kota Medan sebagaimana diuraikan dimuka, dirumuskan permasalahan yang akan dikaji dalam penelitian ini faktor - faktor apakah yang mempengaruhi Pengembangan Ekonomi Lokal (PEL) Kota Medan?

Penelitian ini mencoba menggabungkan berbagai aspek program Pengembangan Ekonomi Lokal. Relevan dengan permasalahan yang dirumuskan dalam kajian penelitian ini, maka tujuan penelitian ini diarahkan untuk untuk mengetahui faktor - faktor yang mempengaruhi Pengembangan Ekonomi Lokal (PEL) Kota Medan.

\section{METODE PENELITIAN}

Metode penelitian yang dilakukan dalam penelitian ini adalah metode penelitian deskriptif Kuantitatif. Pengumpulan data dilakukan dengan menggunakan data sekunder dan primer. Kemudian di analisis yang digunakan untuk menguji hipotesis penelitian yang telah ditetapkan dengan menggunakan data sampel yang diperoleh. Metode Statistik Inferensial yang digunakan dalam analisis data penelitian ini adalah Structural Equation Modeling (SEM). kajian penelitian inidiilustrasikan sebagai berikut: 


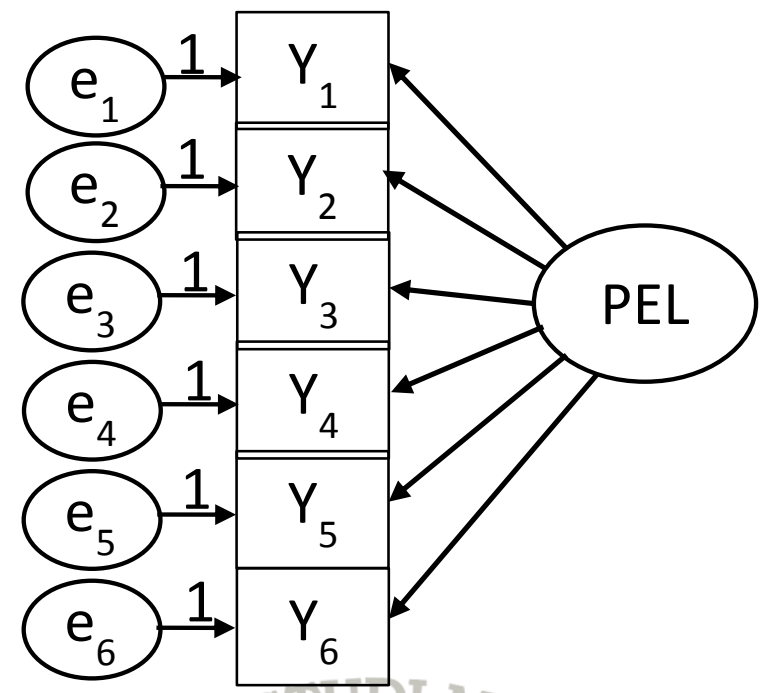

Gambar 1. Hubungan Variabel

Faktor Pengembangan Ekonomi Lokal (PEL) dapat dituliskan dalam model persamaan sebagai berikut:

$\mathrm{Y}_{1}=\lambda_{1} \mathrm{PEL}+\mathrm{e}_{1}$

$\mathrm{Y}_{2}=\lambda_{2} \mathrm{PEL}+\mathrm{e}_{2}$

$\mathrm{Y}_{3}=\lambda_{3} \mathrm{PEL}+\mathrm{e}_{3}$

$\mathrm{Y}_{4}=\lambda_{4} \mathrm{PEL}+\mathrm{e}_{4}$

$\mathrm{Y}_{5}=\lambda_{5} \mathrm{PEL}+\mathrm{e}_{5}$

$\mathrm{Y}_{6}=\lambda_{6} \mathrm{PEL}+\mathrm{e}_{6}$

Keterangan :

$\mathrm{Y}_{1}$ : Modal sosial ;

$\mathrm{Y}_{2}$ : Pendidikan dan Keahlian:

$\mathrm{Y}_{3}$ : Karakteristik Sosial \& Ekonomi;

$\mathrm{Y}_{4} \quad$ : Pasar Tenaga Kerja;

$Y_{5} \quad$ : Kebijakan Pengembangan Ekonomi;

$\mathrm{Y}_{6}$ : Karekteristik Geografis;

PEL : Pengembangan Ekonomi Lokal

\section{HASIL ANALISIS DAN PEMBAHASAN}

Pembangunan ekonomi lokal dalam penelitian ini dijelaskan dengan menggunakan enam dimensi sebagai variabel laten, di mana masing - masing dimensi dikur denngan menggunakan tiga variabel manifestasi yang ditransformasikan ke dalam bentuk kuesioner penelitian. Hasil pengukuran ke enam dimensi pengembangan ekonomi lokal di 21 wilayah Kecamatan se-Kota Medan dideskripsikan melalui Tabel 2. berikut ini.

Tabel 2. Statistik Deskriptif Pengembangan Ekonomi Lokal di Kota Medan

\begin{tabular}{|l|l|c|c|c|}
\hline No & \multicolumn{1}{|c|}{ Variabel Laten } & $\begin{array}{c}\text { Jumlah Variabel } \\
\text { Manifestasi }\end{array}$ & Rata-rata & Standar Deviasi \\
\hline 1 & Modal sosial & 3 & 8.99 & 3.30 \\
\hline 2 & Pendidikan dan Keahlian & 3 & 9.81 & 3.17 \\
\hline 3 & Karakteristik Sosial - Ekonomi & 3 & 7.65 & 2.95 \\
\hline 4 & Pasat tenaga kerja & 3 & 9.18 & 3.18 \\
\hline 5 & $\begin{array}{l}\text { Kebijakan pengembangan ekonomi } \\
\text { lokal }\end{array}$ & 3 & 7.67 & 2.81 \\
\hline 6 & Karakteristik Geografis & 3 & 9.39 & 3.44 \\
\hline
\end{tabular}


Tabel 2 di atas mendeskripsikan bahwa secara rata - rata tedapat tiga variabel laten yang menjelaskan pengembangan ekonomi lokal di 21 wilayah Kecamatan se-Kota Medan memiliki kencederungan berkreteria kurang baik atau kurang berpotensi untuk diimplementasikan. Hal ini terlihat dari rata-rata skor masing-masing variabel lebih kecil dari skor ambang batas tengah 9. Adapun ketiga variabel laten dimaksud, meliputi : modal sosial, karakteristik sosial-ekonomi, dan kebijakan pengembangan ekonomi Namun demikian bila dilihat dari perspektif pendidikan dan keahlian, pasar tenaga kerja dan karakteristik geografisyang lebih besar dari skor ambang batas tengah 9, mengindikasikan Kota Medan berpontensi untuk menerapkan program pengembangan ekonomi lokal di dalam mengali berbagai potensi sumber daya yang ada di Kota Medan.

Hipotesis penelitian ini menyatakan "Modal sosial, Pendidikan dan keahlian, Karakteristik sosial, Pasar tenaga kerja, Kebijakan pengembangan ekonomi dan budaya lokal merupakan enam faktor yang mempengaruhi suksesi implementasi program pengembangan ekonomi lokal Kota Medan".

CFA pengembangan ekonomi lokal dalam penelitian ini dirangkum dari Kitson (2004) dan pandangan ILO (2005), yakni : Modal sosial $\left(\mathrm{Y}_{1}\right)$; Pendidikan dan keahlian; Karakteristik sosial; Pasar tenaga kerja; Kebijakan pengembangan ekonomi dan budaya lokal. CFA ke enam faktor yang mempengaruhi pengembangan ekonomi local di Kota Medan ditunjukkan melalui Output Amos seperti terlihat pada Gambar 2 dan Tabel 3 di bawah ini

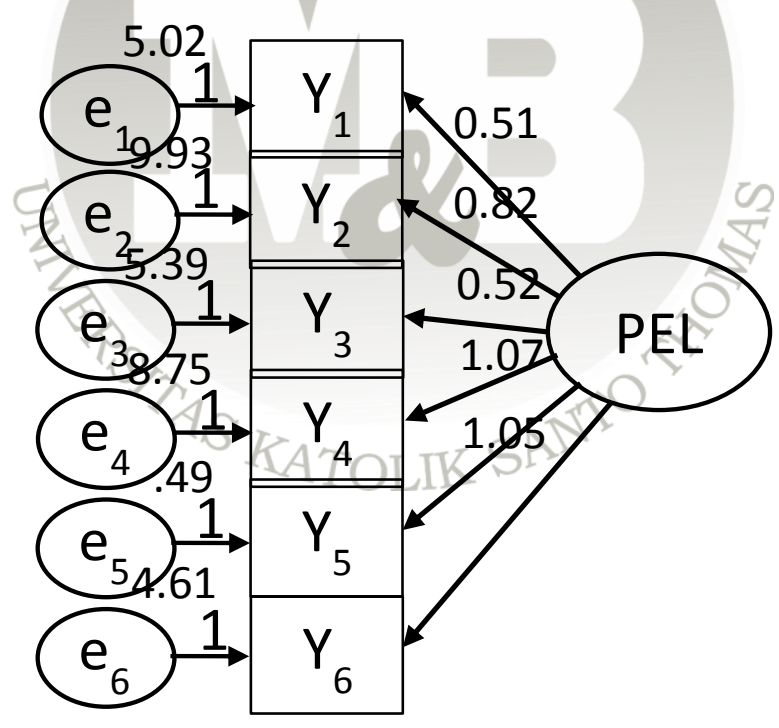

Gambar 2. CFA dan Output Amos

Transformasi gambar di atas kedalam model matematis :

$\mathrm{Y}_{1}=1.00 \mathrm{PEL}+5.02 \ldots \ldots \ldots \ldots \ldots \ldots \ldots \ldots \ldots \ldots \ldots \ldots$ (pers 1$)$

$\mathrm{Y}_{2}=0.51 \mathrm{PEL}+9.93$

(pers.2)

$\mathrm{Y}_{3}=0.82 \mathrm{PEL}+5.39$

(pers 3)

$\mathrm{Y}_{4}=0.52 \mathrm{PEL}+8.75$

(pers 4)

$\mathrm{Y}_{5}=1.07 \mathrm{PEL}+0.49$

$\mathrm{Y}_{6}=1.05 \mathrm{PEL}+4.61$

(pers 6)

Tabel 3.Goodness of Fit Confirmatory Factor Analysis Konstruk Endogen Pengembangan Ekonomi Lokal

\begin{tabular}{|l|c|c|c|}
\hline \multicolumn{1}{|c|}{ Goodness Of Fit Index } & Cut-off Value & Hasil model & Keterangan \\
\hline Chi-Square & $\leq 16.919$ & 13.459 & Baik \\
\hline Probabilitas & $\geq 0.05$ & 0.143 & Baik \\
\hline
\end{tabular}


Volume 17 Nomor 1

\begin{tabular}{|l|c|c|c|}
\hline \multicolumn{1}{|c|}{ Goodness Of Fit Index } & Cut-off Value & Hasil model & Keterangan \\
\hline CMIN/DF & $\leq 2.00$ & 1.495 & Baik \\
\hline GFI & $\geq 0.90$ & 0.979 & Baik \\
\hline TLI & $\geq 0.95$ & 0.985 & Baik \\
\hline CFI & $\geq 0.95$ & 0.991 & Baik \\
\hline RMSEA & $\geq 0.08$ & 0.049 & Baik \\
\hline
\end{tabular}

${ }^{*} \chi^{2} \mathrm{df} 9 \alpha 5 \%=16.919$

Pengujian yang menggunakan confirmatory factor analysis menunjukkan bahwa model ini dapat diterima.Tingkat signifikansi dari confirmatory factor analysis konstruk endogen pengembangan ekonomi local adalah sebesar 0.143 menunjukkan bahwa hipotesa nol yang menyatakan bahwa tidak terdapat perbedaan antara matriks kovarians sampel dan matriks kovarians populasi yang diestimasi tidak dapat ditolak dan karena itu model ini dapat diterima.Dengan demikian Confirmatory Factor Analysis konstruk eksogen menunjukkan bahwa model dapat diterima.

Nilai dari koefisien regresi untuk masing-masing indikator akan memenuhi syarat jika nilai Critical Ratio di atas 1,96. Critical Ratio atau C.R. C.R. adalah identik dengan t-hitung dalam analisis regresi. Oleh karena itu C.R. yang lebih besar dari 1,96 menunjukkan bahwa variabel-variabel itu signifikan pada taraf signifikansi 5\% dan merupakan dimensi dari faktor latent yang dibentuk Regression weight konstruk eksogen dari confirmatory factor analysis yang dapat dilihat pada Tabel 4. Tabel ini menunjukkan bahwa faktor loading masing-masing indikator sudah menunjukkan tingkat penerimaan di atas 0,40. Hair et al. (1998) menyatakan syarat suatu indikator yang merupakan dimensi dari suatu variabel bentukan adalah jika loading factor -nya lebih dari 0,4. Berdasarkan hal tersebut maka faktor loading masing-masing indikator dapat diterima dan layak untuk dianalisis.

Tabel 4. Regression Weights Confirmatory Factor Analysis Konstruk Endogen Pengembangan Ekonomi Lokal

\begin{tabular}{|c|c|c|c|c|c|c|}
\hline & & \multicolumn{2}{|c|}{ Estimate } & S.E. & C.R. & P. \\
\hline$\overline{\mathrm{Y} 1}$ & $<-$ & $Y$ & 1.000 & & & \\
\hline$Y 2$ & $<-$ & $\mathrm{Y}$ & .512 & .095 & 5.413 & 0.000 \\
\hline$Y 3$ & $<--$ & Y & .819 & .083 & 9.838 & 0.000 \\
\hline$Y 4$ & $<--$ & Y & .519 & .090 & 5.791 & 0.000 \\
\hline Y5 & $<--$ & $\mathrm{Y}$ & 1.066 & .077 & 13.911 & 0.000 \\
\hline Y6 & $<-$ & Y & 1.051 & .090 & 11.625 & 0.000 \\
\hline
\end{tabular}

\section{PEMBAHASAN}

Pada hakekatnya PEL dapat diartikan sebagai suatu proses pembangunan ekonomi dimana stakeholders endogeneous (pemerintah, swasta, dan masyarakat) yang berperan aktif dalam mengelola sumber daya lokal untuk menciptakan lapangan kerja dan memberikan stimulus pada pertumbuhan ekonomi di wilayahnya. Kitson (2004) mengindentifikasi 5 (lima) faktor suksesi implementasi program PEL, yaitu : 1) social capital; 2) education Skill; 3) labour market; 4) social character; dan 5) economic development policy. Kelima faktor di atas selanjutnya dijadikan sebagai faktor untuk mengkonfirmasi suksesi implmentasi program PEL didalam menggali berbagai potensi yang dimiliki Kota Medan.

Hasil analisis statistik deskrptif dalam penelitian yang dilakukan terhadap kelima faktor yang mempengaruhi suksesi implmentasi PEL di Kota Medan mencerminakan bila dilihat dari faktor modal sosial karakteristik sosial-ekonomi dan kebijakan pengembangan ekonomi, program PEL masing kurang mendukung untuk diimplementasikan di Kota Medan, Namun bila dilihat dari faktor pendidikan dan keahlian serta pasar tenaga kerja, program PEL sangat 
memungkinkan diimplementasikan didalam menggali berbagai potensi yang dimiliki wilayah Kota Medan.

Hasil analisis faktor yang dilakukan dalam penelitian ini menjustifikasi kelayakan kelima faktor di atas didalam menjelaskan suksesi implementasi program PEL di Kota medan, hal ini terlihat dari seluruh nilai CR yang lebih besar dari pada nilai kritis dengan tingkat signifikansi sebesar $5 \%$ yang bernilai 1,96 dan probabilitasnya (P) lebih kecil dari $\alpha 5 \%$. Justifikasi ini sekaligus membukti diterimanya hipotesis penelitian ini yang menyatakan : "Modal sosial, Pendidikan dan keahlian, Karakteristik sosial, Pasar tenaga kerja, Kebijakan pengembangan ekonomi dan budaya lokal merupakan enam faktor yang mempengaruhi suksesi implementasi program pengembangan ekonomi lokal Kota Medan", artinya pengembangan ekonomi lokal akan terimplementasi dengan baik apabila didukung dengan modal sosial, pendidikan dan keahlian, karakteristik sosial, pasar tenaga kerja, kebijakan pengembangan ekonomi dan budaya lokal yang baik. Pandangan ini konsisten dengan Rogerson, 2003 seperti dikutip dalam Rivett, 2008; dan RPJMN Indonesia 2010 - 2014 serta konsisten dengan temuan penelitian Kitson, et. al. (2004); Hayduk (1987); Kline (1996); Loehlin (1992); dan Long (1983).

Presiden Susilo Bambang Yudoyono dalam kapasitasnya sebagai kepala negara sekaligus kepala pemerintahan, dalam sambutannya pada acara Silaknas ICMI tanggal 8 Desember 2006 menekankan :"Dimensi kewilayahan, desentralisasi, pemberdayaan potensi lokal, harus menjadi cara berfikir, 'ideologi', dan langkah pembangunan kita. Kita harus lebih peduli pada local economic development daripada yang serba global, serba nasional." Namun demikian, sambutan Presiden Susilo Bambang Yudoyono di atas, belum sepenuhnya dapat diimplementasikan di Indonesia. Hingga tahun 2010 tercatat dari 33 Propinsi dan 504 Kabupaten/Kota yang ada di Indonesia masih hanya tujuh Kabupaten/Kota yang mengimplementasikan program PEL didalam menggali potensi yang ada di daerahnya, dan satu diantaranya Kota Medan yang merupakan Kota terbesar ketiga setelah Jakarta dan Surabaya belum mengimplementasikan program PEL didalam menggali berbagai potensi yang dimiliki.

\section{KESIMPULAN}

dan pembasan dilakukan dalam kajian penelitian ini disimpulkan:

1. Tiga variabel memiliki rata-rata skor masing - masing variabel lebih kecil dari skor ambang batas tengah 9. Adapun ketiga variabel laten dimaksud, meliputi : modal sosial, karakteristik sosial-ekonomi, dan kebijakan pengembangan ekonomi. Namun demikian bila dilihat dari perspektif pendidikan dan keahlian, pasar tenaga kerja dan karakteristik geografis yang lebih besar dari skor ambang batas tengah 9 .

2. Modal sosial, pendidikan dan keahlian, karakteristik sosial, pasar tenaga kerja, kebijakan pengembangan ekonomi dan budaya local merupakan enam faktor yang berpengaruh positif dan signifikan terhadap suksesi implementasi program pengembangan ekonomi lokal Kota Medan.

\section{DAFTAR PUSTAKA}

Adisasmita, Rahardjo H., 2005, Dasar-Dasar Ekonomi Wilayah, Graha Ilmu, Yogyakarta. 2008, Pengembangan Wilayah : Konsepdan Teori, Graha Ilmu, Yogyakarta.

Adiningsih, Sri, 2002. Regulasi Dalam Revitalisasi Usaha Kecil dan Menengah, UGM

Adjie, Mas Wedar, H. 2011. 'Konsep Ekonomi Lokal Perkotaan". Sosialisasi Pengembangan Ekonomi Lokal Perkotaan Se-Provinsi Riau, 18 Juli 2011, Hotel Gtand Elite, Pekan Baru, Riau.. 
Ardiana, I.D.K.R. dan Brahmayanti, I.A. Subaedi, 2010."Kompetensi SDM UKM dan Pengaruhnya Terhadap Kinerja UKM di Surabaya". Jurnal Manajemen Dan Kewirausahaan, VOL.12, NO. 1, hal. 42-55

Alters, Theo, and Van Mark, Ronald, 1986, The Regional Development Potensial of SMEs: A European Perspective, Routledge.

Amstrong, H., dan J. Taylor. 2000. Regional Economics and Policy. Third Edition. Blackwell Publishing : Oxford.

Anderson, J.C. and D.W. Gerbing, 1988. "Structural Equation Modeling in Practice : A Review and Recommended Two-Step Approach", Psycological Bulletin.103 (3) : 411-23

Ardiana, I.D.K.R. dan Brahmayanti, I.A. Subaedi, 2010."Kompetensi SDM UKM dan Pengaruhnya Terhadap Kinerja UKM di Surabaya". Jurnal Manajemen Dan Kewirausahaan, VOL.12, NO. 1, hal. 42-55

Bappenas. 2006. Panduan Nasional Revitalisasi Pengembangan Ekonomi Lokal. Deputi Bidang Pengembangan Regional dan Otonomi Daerah. Jakarta.

Badrudin, Rudy. 2012, "Pengembangan ekonomi lokal kabupaten/kota Provinsi Daerah Istimewa Yogyakarta Menggunakan tipologi klasen dan Location quotient" , JRMB, Volume 7, No.1 Juni 2012, h 17-3

Blakely, EJ \& Bradshaw, TK, 2002, Planning Local Economic Development, Theory and Practice, Sage Publications, California.

Bond, Richard, Curran, Jahanna, Kirk Patrick, Lece, Norman, Francis, Paul. 2001. Integrated Impact Assessment for Sustainable Development, A Case Study Approach. University of Manchester. UK

Brown, Donald. 1995. Poverty-Growth Dichotomy, dalam Üner Kirdar dan Leonard Silk (ed.). People: From Impoverishment to Empowerment. New York University Press : New York.

Clarke, S. E. \& Gaile, G. L. 1998 The Work of Cities, University of Minnesota Press: Minneapolis.

Daou, Alain and Karuranga, Egide, 2012. "Success of Smes in Emerging Economies: Propositions for Future Research", Québec (Québec) G1V 0A6, Canada : Laval University, FSA, Department MNG.

DPLG 2006a. Stimulating and developing sustainable local economies: National framework for local economic development (LED) in South Africa. Pretoria: DPLG. 166

Farhady, H and Hatch, E. 1981. Research Design and Statistics for Applied Linguistics. University of California.. Newbury Hous e Publisher. Inc : Los Angles

Ferdinand, A.T., 2002, Structural Equation Modelling dalam Penelitian Manajemen, Badan Penerbit Diponegoro, Semarang. , 2006, Metode Penelitian Manajemen, BP UNDIP, Semarang.

Friedman, John \& Weaver, Clyde. 1979. Territory \& Function - The Evolution of Regional Planning. Edward Arnold, London.

Frinces, Z. Heflin, 2010, Be An Entrepreneuer (Jadilah Seorang Wirausaha) Kajian Strategi Pengembangan Kewirausahaan, Graha Ilmu, Yogyakarta.

Glasson J. 1978. An Introduction to Regional Planning, Concepts, Theory and Practice. The Anchor Press Ltd : Great Britain.

Giaoutzi, Maria, Peter Nijkamp and David J. Storey (1988), Small and Medium Size Enterprises and Regional Development, Routledge, London. 
Ghozali, Imam, 2005, Aplikasi Analisis Multivariate dengan Program SPSS, Badan Penerbit Universitas Diponegoro, Semarang.

Gibb, Lucio Carlos Freire, 2011, "Entrepreneurial Dynamics In Local Economic Development",PhD Thesis,Denmark.: Department of Development and Planning Aalborg University.

Gujarati, D.1999. Essential of Econometrics, Second Edition, McGraw-Hill.Inc, London.

Hair, J. F., Jr., et. al. 1995, Multivariate Data Analysis with Reading, 4rd Edition, Prentice-Hall International Inc., New Jersey.

Hariyoga, Himawan, 2007. "Kebijakan Revitalisasi Pengembangan Ekonomi Lokal", Workshop Nasional dan Pameran Cluster Unggulan Jawa Tengah, Gedung Grhadhika Bhakti Praja, Semarang, 25-26 April 2007.

Hayter, Roger (2000), The Dinamic of Indusrial Location: The Factory, The Firm, and The Production System, John Willey and Sons : New York.

Helming, A.H.J.,2003, Local economic Development, New Generations of Actors Policies and Instruments for Africa, Public Administration and Development.

Idris, Indra, 2007. "Pengembangan Ekonomi Lokal Daerah Perbatasan Melalui Pemberdayaan UKM". Pengkajian Produk Unggulan Dalam meningkatkan Ekspor UKM dan Pengembangan Ekonomi Lokal, Jakarta : Deputi Pengkajian Sumberdaya UKMK, hal 1-6

James, Sara-Beth; Thomas W. Ilvento and Steven E. Hastings, 2002, " The Effect of Local Economic Development Policy on Employment Growth in Rural Counties in the MidAtlantic Region", FREC SP02-04, Newark : Department of Food and Resource Economics, University of Delaware

Jhingan, ML, 1998, Ekonomi Pembangunan dan Perencanaan, diterjemahkan oleh D.Guritno, Edisi ke Tujuh, PT. Raja Grafindo Persada, Jakarta.

Kirdar, Uner dan Leonard Silk (ed.) 1995. People: from Impoverishment to Empowerment. New York University Press, New York.

Kim, Sung Tai. 1997. "The Role of Local Public Sectors in Regional Growth in Korea", Asian Economic Journal, Vol. 11 No. 21, 155-168.

Kimura, Fukunari, 2002, "Subcontracting and Performance of Small and Medium Firm in Japan", Small Business Economics 18: 163-175.

Kitson J, Martin R, Tayler P. 2004, “Regional Competitiveness : An Elusive Yet Key Concept", Regional Studies, 38 (9), pp. 991-999.

Kartasasmita, G.1996. Pembangunan untuk Rakyat: Memadukan Pertumbuhan dan Pemerataan. CIDES, Jakarta.

Lestari, Sri Hs, 2007. Kajian efektivitas model penumbuhan klaster bisnis ukm berbasis agribisnis". Pengkajian Produk Unggulan Dalam meningkatkan Ekspor UKM dan Pengembangan Ekonomi Lokal, Jakarta : Deputi Pengkajian Sumberdaya UKMK, hal. 1-25

Liu, Hongxia \& Fong, Michelle, 2010. “The Corporate Social Responsibility Orientation of Chinese Small and Medium Enterprises", Journal of Business Systems, Governance and Ethics, Vol 5 No. 3, P 33- 50

Lussier, Robert N, 2002, "Reasons Why Small Business Fail: And to Avoid Failure", The Entrepreneourial Executive, 1 (2) : 10 - 18.

Martin, Ravallion. 2001. Poverty Comparisons. World Bank. New York 
Meyer, Stamer, J. 2006. The Hexagon of Local Economic Development and LED in South Africa. Mesopartner: Duisburg.

Mitchel, B. 1997. Resource and Environmental Management. University of Ontario, Ontario. Waterloo

Munasinghe M. 1993. Environmental Economics and Sustainable Development. The International Bank for Reconstruction and Development, The World Bank, Washington, DC USA.

Musakwa.W.2008. "Local Economic Development as a Poverty alleviation tool: A case on the urban renewal KwaMashu". Masters Dissertation, University of Kwazulu Natal.

Myrdal, G, 1957, Economic Theory and Underdevelopment Regions, London.

Nair, Jayesh, 2007. "Practicalities around Black Economic Empowerment and Small and Medium Enterprises in South Africa", Desertasi, South Africa : University of Pretoria.

Nasikun, 1996. Urbanisasi dan Kemiskinan di Dunia Ketiga. PT. Tiara Wacana.Yogyakarta..

Nazir, Moh. 2005. Desain Penelitian. Gramedia Pustaka Utama : Jakarta.

Nel, E. \& Rogerson, C.M. (eds.) 2005. Local Economic Development in the Developing World: The Experience of Southern Africa. Transaction Publishers: New Brunswick, N.J.

Nel, E., Hill, T. R., \& Goodenough, C. 2007. Multi-stakeholder driven local economic development: reflections on the experience of Richards Bay and the uMhlathuze municipality. Urban Forum, 18, 31-47.

Nugroho, Dahuri. (2004), Pembangunan Wilayah Perspektif Ekonomi, sosial, dan Lingkungan, Pustaka LP3ES Indonesia, Jakarta.

Onugu, Basil Anthony Ngwu, 2005. "Small and Medium Enterprises (SMES) in Nigeria: problems And prospects", Dissertation, Nigeria: St. Clements University.

Piore M dan Sabel C. 1984. The Second Industrial Divide: Possibilities for Prosperity. Basic Book: New York

Ravetz, J. 2000. City-Region 2020 -Integrated planning for a sustainable environment. Earthscan Publications Ltd. London.

Republik Indonesia, 2008. Undang - Undang Republik Indonesia Nomor 20 Tahun 2008, tentang Usaha Mikro, Kecil dan Menengah, Jakarta.

Richardson, Harry W. 1991. Dasar-Dasar Ilmu Ekonomi Regional. Terjemahan Paul Sitohang. LPFE - UI. Jakarta.

Riyanti, B.P.D., 2003. Kewirausahaan Dari Sudut Pandang Psikologi Kepribadian. Grasindo: Jakarta.

Roderic, G. Meppem, Tony. 1997. Planning for Sustainability as a Learning Concept. New England Ecological Economic Group. Center for Water Policy Research. University of New England. Armidale. Australia.

Rogerson, Robert J, 2003. Qualty of Live, Place and Global City dalam Yuan, Lim Lan et.als (ed). Urban Quality of Life. Critical Issues and Options. School of Building and Real Etate, National University of Singapore

Rustiadi E. et al. 2009. Perencanaan dan Pengembangan Wilayah, Crestpent Press dan Yayasan Obor Indonesia, Jakarta.

Sekaran U., 2002. Research Methods for Bussiness a skill Building Approach, Third Edition, New York : John Willey \& Sons, Inc. 
Shaikh, Khalid Hussain; Ghumro, Ikhtiar Ahmed; Shah, Asif Ali; Shaikh, Faiz. M. \& Afridi Tahira, 2012. "Empowerment Of Women Through Small And Medium Enterprises (SMES) In Rural Sindh" Asian Journal of Business and Management Sciences, Vol. 1 No. 4 [128-133]

Siregar, Hermanto dan Wahyuniarti, Dwi 2006, “Dampak Pertumbuhan Ekonomi Terhadap Penurunan Penduduk Miskin di Indonesia : Proses Pemerataan dan Pemiskinan", Direktur Kajian Ekonomi, Institut Pertanian Bogor

Sirojuzilam, 2008, Disparitas Ekonomi \& Perencanaan Regional, Ketimpangan Ekonomi Wilayah Barat \& Wilayah Timur Provinsi Sumatera Utara, Pustaka Bangsa Press, Medan. , 2011. Problematika Wilayah: Kota dan Daerah, USU Press, Medan.

Suryana, Yuyus dan Kartib Bayu, 2010, Kewirausahaan, Pendekatan Karakteristik Wirausahaan Sukses, Kencana Prenada Media Group, Jakarta.

Tambunan, Tulus, 2000, Development of Small Scale Industries during the New Order Government in Indonesia, Ashgate Publishing Ltd, England.

Tambunan, Tulus, 2002, Usaha Kecil dan Menengah di Indonesia: Beberapa Isu Penting, Penerbit Salemba Empat, Jakarta.

Tambunan, Tulus T.H. 2003. Perekonomian Indonesia: Beberapa Masalah Penting. Ghalia Indonesia, Jakarta.

Tambunan, Togap dan Nasution Paruhuman, 2006. "Peningkatan Daya Saing Usaha Kecil dan Menengah Yang Berbasis Pengembangan Ekonomi Lokal". Jurnal Pengkajian Koperasi dan UKM, Nomor 2 Tahun - I, hal 26-40

Tarigan, Robinson. 2004. Ekonomi Regional: Teori dan Aplikasi. Bumi Aksara, Jakarta. 2007, Ekonomi Regional Teori dan Aplikasi, Edisi Revisi, Cetakan Keempat, Jakarta: Bumi Aksara.

Urata, Shujiro, 2001. Policy Recommendation for SME Promotion in the Republic of Indonesia, JICA, Tokyo

Zimmerer, TW dan Scarborough, NM, 1998, Essential of Entrepreneur and Small Business Management. 2th Edition, Prentice Hall. 